\title{
Computed tomography-guided bupivacaine and corticosteroid injection for the treatment of symptomatic calcification in the great toe tendon
}

This article was published in the following Dove Press journal:

Local and Regional Anesthesia

29 April 2014

Number of times this article has been viewed

\author{
Omer Karatoprak' \\ Sinan Karaca ${ }^{2}$ \\ Mehmet Nuri Erdem ${ }^{3}$ \\ Ozgur Karaman ${ }^{2}$ \\ Azmi Hamzaoglu ${ }^{4}$ \\ 'Department of Orthopedic Surgery, \\ Kadikoy Florence Nightingale \\ Hospital, Istanbul, Turkey; \\ ${ }^{2}$ Department of Orthopedic Surgery, \\ Fatih Sultan Mehmet Training \\ and Research Hospital Atasehir, \\ Istanbul, Turkey; ${ }^{3}$ Department of \\ Orthopedics and Traumatology, Kolan \\ International Hospital Sisli, Istanbul, \\ Turkey; ${ }^{4}$ Department of Orthopedic \\ Surgery, Istanbul Florence Nightingale \\ Hospital, Istanbul Turkey
}

Correspondence: Sinan Karaca

Department of Orthopedic Surgery,

Fatih Sultan Mehmet Training

and Research Hospital Atasehir,

Istanbul, Turkey

Tel +902164500303

Fax +902164501950

Email mdsnn@hotmail.com
Background: Calcification in the great toe tendon is a rare disorder that is characterized by the deposition of calcium on degenerative collagen fibrils.

Case presentations: In this report, we present two cases of calcific tendonitis: one in the adductor hallucis and the other in the flexor hallucis longus tendon. We preferred computed tomography-guided steroid injection in our cases because of pain unresponsive to conservative treatment. Patients were free of symptoms at the follow-up visit, 4 weeks after injection.

Conclusion: Calcification of the hallux tendons is a rare disorder. Treatment of tendonitis consists of nonsteroidal anti-inflammatory drugs. Local anesthetic and steroid injection may be considered in cases unresponsive to conservative treatment. Because of the anatomic location of tendons, injection could be difficult. Computed tomography guidance may improve the success rate of injections.

Keywords: bupivacaine, calcification, great toe tendons, corticosteroid injection

\section{Introduction}

Calcification in the hallux tendons is characterized by deposition of calcium on the collagen fibrils of the tendons. It was first described on the semitendinosus tendon ${ }^{1}$ and is mostly observed in the supraspinatus tendon of the shoulder and, less frequently, in the hip, elbow, wrist, and knee. ${ }^{1,2}$ It usually presents with pain and tenderness, and diagnosis is established by the demonstration of calcifications within the soft tissue. ${ }^{3}$ There is only one case of calcific tendonitis around the metatarsophalangeal joint reported in the previous literature that involved the abductor hallucis brevis tendon. ${ }^{4}$ To our knowledge, this is the first report that shows the treatment of calcification in the hallux tendons by computer tomography (CT)-guided local steroid injection.

\section{Case presentations Case I}

A 55-year-old woman presented with dorsal edema associated with severe pain in the first three inter-digital web spaces and difficulty with bearing weight on her right foot. She did not have a history of trauma or sprain. Edema on the dorsum of her foot and tenderness on the plantar surface of the first three inter-digital web spaces were noted on physical examination. A mild increase of local temperature and erythema were also observed. Range of motion in the ankle was within normal limits, but movements of the great toe were painful. Hallux valgus deformity was determined in both her feet, which required surgical treatment. Magnetic resonance imaging (MRI) with and without contrast material showed inflammatory edema, both on the plantar surface of 
the foot and in the deep flexor compartment of the adductor hallucis muscle. CT examination revealed a calcification in the distal musculotendinous junction (size, $6.4 \times 4.3 \mathrm{~mm}$ ) of the adductor hallucis tendon, which confirmed the diagnosis of calcific tendonitis.

Hemoglobin, hematocrit, erythrocyte sedimentation rate, C-reactive protein, and alkaline phosphatase levels were investigated to exclude infection; all were within normal limits.

\section{Case 2}

A 52-year-old woman presented with pain on the plantar surface and inability to bear weight on her right foot. She did not have a history of trauma. Her symptoms had worsened within the last 2 weeks. Her physical examination revealed severe tenderness on the plantar surface of her foot. No local increases of temperature or erythema were determined. Range of motion in her ankle was normal, but active and passive movements of the hallux were painful. She had a bilateral hallux valgus deformity, which did not necessitate surgical intervention. MRI with and without contrast and CT examination showed calcification (size, $7.2 \times 3.8 \mathrm{~mm}$ ) in the plantar surface of the foot beneath the flexor hallucis longus tendon and was also diagnosed as calcific tendonitis.

Hemoglobin, hematocrit, erythrocyte sedimentation rate, C-reactive protein, and alkaline phosphatase levels were investigated to exclude infection; all were within normal limits.

When calcific tendonitis was diagnosed with physical examination, conservative treatment was prescribed for the patient, including diclofenac sodium, $75 \mathrm{mg} /$ day for 1 week, and ankle-foot orthosis for 2 weeks without weight bearing.

After unsuccessful conservative treatment, the informed consent of each patient was obtained and CT-guided steroid injection was performed. Patients were placed into a prone position, and after infiltration of local anesthetic (1\% xylocaine) into the skin and subcutaneous tissue under sterile conditions, betamethasone $6 \mathrm{mg}$ and bupivacaine $75 \mathrm{mg}$ were administered into the calcific deposits through an 18-gauge needle. Patients were free of symptoms at the follow-up visit 4 weeks after injection. Patients remained free of symptoms at the 3- and 12-month follow-up visits.

\section{Discussion}

The exact pathogenesis that leads to deposition of calcium hydroxyapatite crystals on the tendons is unknown. ${ }^{1}$ Calcific tendonitis is observed in $3 \%$ of the adult population, and patients may be asymptomatic or may present with an acute or chronic clinical picture. ${ }^{1,4}$ In acute cases, erythema, edema, and arthralgia are common. Severe pain, a local increase of temperature, and tenderness were present in one of our cases involving adductor hallucis. ${ }^{5}$ Severe pain and tenderness were the only physical findings in the case of flexor hallucis longus tendonitis.

The diagnosis is straightforward if calcifications within the tendon are demonstrated by plain X-rays; shoulder, hip, elbow, wrist, and knee are the common sites involved., ${ }^{1,2}$ The disease shows a peak between the fourth and sixth decades and is more common in sedentary people compared with manual laborers. ${ }^{2,3,6}$ Our patients' ages were consistent with the literature.

Tendonitis, stenosing tenosynovitis, tendon degeneration, development of nodules, and partial or complete rupture may develop in the flexor hallucis longus tendon as a result of the anatomic location of the lesion. ${ }^{2,4,6}$ In acute cases, erythema and local increase of temperature are observed in soft tissues. These findings also suggest an infection. ${ }^{1,7}$ Our patients' infection markers were within normal limits. Fracture of the sesamoid bones or sesamoiditis may also mimic symptoms of calcific tendonitis. The diagnosis of calcific tendonitis is established by the demonstration of calcific deposits on or within the tendon substance. ${ }^{4,7}$

MRI is the first choice for imaging acute cases if erythema and edema are associated with pain. The high soft tissue contrast offered by MRI makes it the method of choice to reveal the edema and inflammation associated with calcific tendonitis. ${ }^{6}$ However, the nonspecific findings detected by MRI may also be present in soft tissue infections, malignant lesions, and other soft tissue lesions caused by trauma. MRI is not effective in displaying the pathognomonic finding of calcification. ${ }^{2,6}$ Signal void foci of calcific deposits that are observed in atypical localizations (Figures 1A and 2A), such as the foot, can readily be overlooked if the diagnosis is not kept in mind. CT should be performed for signal void foci observed in the MRI images that had raised the suspicion of calcification (Figures $1 \mathrm{~B}$ and $2 \mathrm{~B}){ }^{5-7}$ Calcific tendonitis was confirmed in our cases presented in this report.

Treatment of calcific tendonitis mainly consists of nonsteroidal anti-inflammatory medication. ${ }^{5,6,8}$ If symptoms are severe or unresponsive to conservative treatment, surgical excision or CT- or fluoroscopy-guided steroid injection may be attempted..$^{5,8}$ We preferred CT-guided steroid injection in our cases because of our CT-guided injection experience and pain unresponsive to conservative treatment. Both of our cases returned to their daily activities 2 weeks after injection. The patients were free of symptoms at the fourth week. 


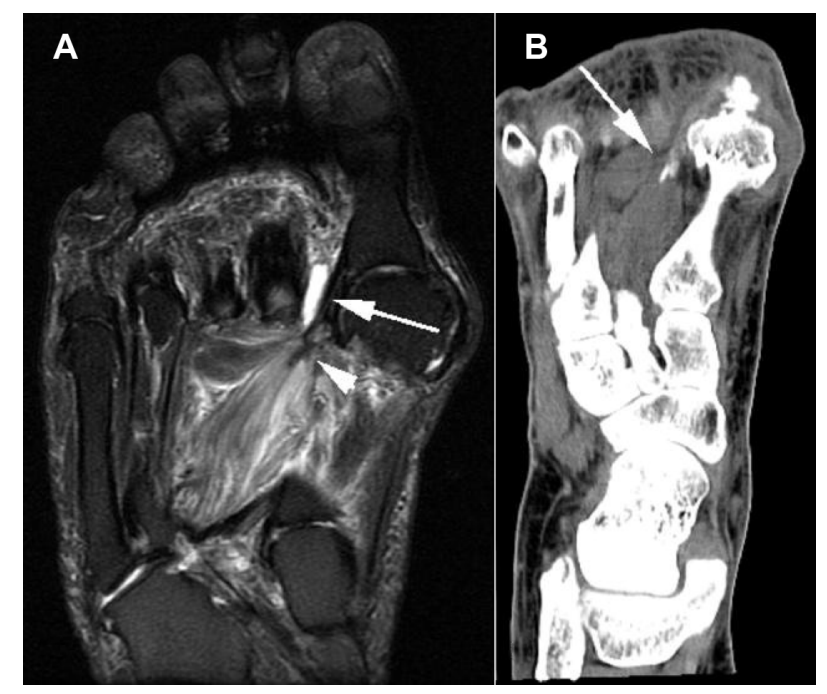

Figure I (A) A fat-saturated fast SE T2 weighted image in the coronal plane demonstrates inflammatory edema in the adductor hallucis longus muscle with a tiny signal void in the distal muscle-tendon junction compatible with calcification (arrowhead). Also note the associated intermetatarsal bursitis in the first interdigital web space (arrow). (B) A coronal reformatted computed tomography image using a soft tissue window reveals a small calcification in the distal muscle-tendon junction of adductor hallucis longus (arrow).

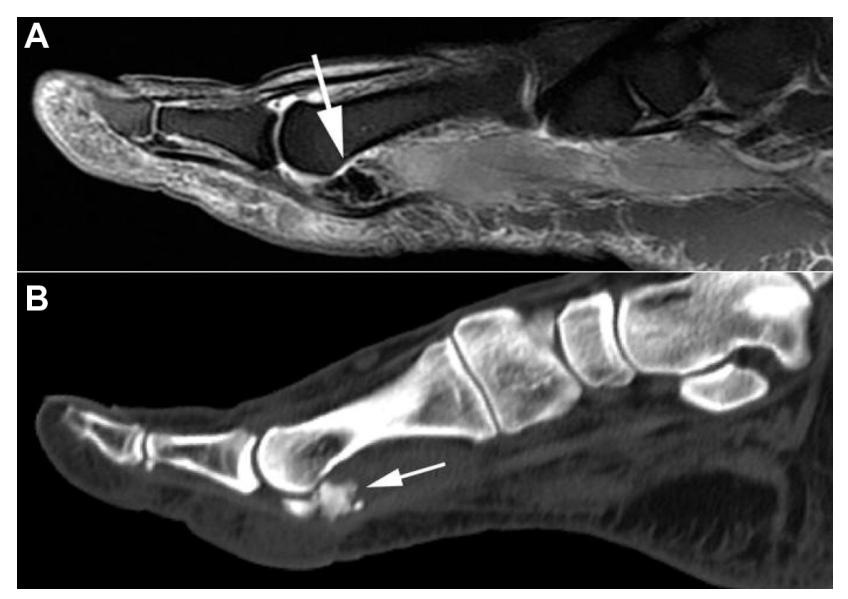

Figure 2 (A) A fat-saturated fast SE T2 weighted sagittal image shows an amorphous signal void area compatible with calcification underneath the flexor tendon of the great toe (arrow). (B) A sagittal reformatted computed tomography image corresponding to Figure $2 \mathrm{~A}$ confirms that the lesion is a calcified mass (arrow).

\section{Conclusion}

In the case of a painful foot that does not respond to conservative measures, local steroid and local anesthetic injection may be used. CT guidance may increase the success of injection.

\section{Disclosure}

The authors report no conflicts of interest in this work.

\section{References}

1. Flemming DJ, Murphey MD, Shekitka KM, Temple HT, Jelinek JJ, Kransdorf MJ. Osseous involvement in calcific tendinitis: a retrospective review of 50 cases. AJR Am J Roentgenol. 2003;181(4): 965-972.

2. Sarkar JS, Haddad FS, Crean SV, Brooks P. Acute calcific tendinitis of the rectus femoris. J Bone Joint Surg Br. 1996;78(5):814-816.

3. Wepfer JF, Reed JG, Cullen GM, McDevitt WP. Calcific tendinitis of the gluteus maximus tendon (gluteus maximus tendinitis). Skeletal Radiol. 1983;9(3):198-200.

4. Tomlinson MP, Williams LA. Extensor hallucis longus calcific tendonitis: a case report. Foot Ankle Int. 2006;27(2):144-145.

5. Choudur HN, Munk PL. Image-guided corticosteroid injection of calcific tendonitis of gluteus maximus. J Clin Rheumatol. 2006;12(4): 176-178.

6. Bui-Mansfield LT, Moak M. Magnetic resonance appearance of bone marrow edema associated with hydroxyapatite deposition disease without cortical erosion. J Comput Assist Tomogr. 2005;29(1): 103-107.

7. Hottat N, Fumière E, Delcour C. Calcific tendinitis of the gluteus maximus tendon: CT findings. Eur Radiol. 1999;9(6):1104-1106.

8. Cox D, Paterson FW. Acute calcific tendinitis of peroneus longus. J Bone Joint Surg Br. 1991;73(2):342.

9. Yang I, Hayes CW, Biermann JS. Calcific tendinitis of the gluteus medius tendon with bone marrow edema mimicking metastatic disease. Skeletal Radiol. 2002;31(6):359-361.

10. Muschol M, Petersen W, Hassenpflug J. Symptomatic calcification of the adductor hallucis tendon at the first metatarsophalangeal joint: report of two cases. Foot Ankle Int. 2006;27(4):296-298.
Local and Regional Anesthesia

\section{Publish your work in this journal}

Local and Regional Anesthesia is an international, peer-reviewed, open access journal publishing on the development, pharmacology, delivery and targeting and clinical use of local and regional anesthetics and analgesics. The journal welcomes submitted papers covering original research, basic science, clinical studies, reviews \& evaluations, guidelines, expert opinion and commentary, case reports and extended reports. The manuscript management system is completely online and includes a very quick and fair peer-review system, which is all easy to use. Visit http://www.dovepress.com/testimonials.php to read real quotes from published authors. 